\title{
Some aspects of the organization of medical and psychological rehabilitation of rescuers in the Republic of Kazakhstan
}

\author{
Aisha Sh. Ibrayeva ${ }^{1}$, Botagoz S. Turdalieva ${ }^{1}$, Gulshara Ye. Aimbetova ${ }^{1}$, Murat K. Koshimbekov ${ }^{1}$, Alfiya I. Igissenova ${ }^{1}$
}

\begin{abstract}
The last decades in the world are characterized by a steady increase in the number of natural and man-made emergencies. The Republic of Kazakhstan is not an exception to the global patterns of emergency situations. In the period from September 4 to October 6, 2017, a comprehensive study of the state of health of 551 rescuers in Almaty (Kazakhstan) was carried out according to reports on registered diseases, their outcomes and causes of temporary disability for 2012-2017, and the need for rehabilitation based on a specially designed questionnaire. The study shows the need to develop effective measures for the organization of medical and psychological rehabilitation of rescuers.
\end{abstract}

Keywords: natural and man-made emergencies, rescuers, medical and psychological rehabilitation

\section{INTRODUCTION}

The work of a rescuer in dealing with the aftermath of natural and man-made emergencies is one of the most dangerous professions characterized by high traumatism and mortality. On average, 17.7 thousand emergency situations are registered in Kazakhstan annually. Rescue services are the first to respond during emergencies, and the professional duties of rescuers are related to the performance of physically and psychologically hard work.

The working conditions of rescuers are characterized by considerable physical exertion, exposure to extreme temperatures, various toxic substances, etc. (1-4). An analysis of foreign literature shows, that the direct fulfillment of professional duties (for example, extinguishing fires) is associated with a quarter of all accidents, as well as respiratory system diseases and oncological diseases. One-third of those whose professional activities are associated with high risk are observed non-specific abnormalities, accompanied by a moderate decrease in the functional reserves of the body, state of neuro-psychological stress and, in general, stress adaptation mechanisms (5-7). A high incidence of depressive state and post-traumatic mental disorders is noted in liquidators of the consequences of the collapse of the New York shopping center (8). As possible social risks and medico-psychological consequences are most often mentioned: increased frequency and complication of clinical manifestations of post-traumatic stress disorders; an increase in the incidence of chronic alcohol intoxication; drug abuse; the emergence of family conflicts; diseases of a psychogenic nature, obtained during the performance of official duties; the increase in the number of cases of inadequate aggressive reactions and suicidal behavior (9).

Thus, work in conditions of emergency situation leads to pronounced violations, which are manifested, on the one hand, in somatic pathology, and on the other, in the deterioration of psychophysiological indicators and changes in psychological status, which indicates the need for the organization of rehabilitation for rescuers working in acute and chronic stress conditions.

1 Asfendiyarov Kazakh National Medical University, Almaty, Kazakhstan.

Received: 21 Sep 2019, Accepted: 14 Nov 2019

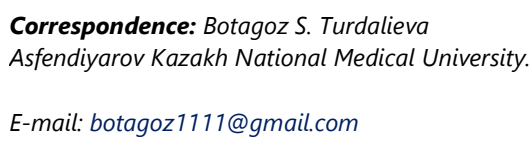

E-mail:botagoz1111@gmail.com

(C) 2019 by the authors; licensee Modestum Ltd., UK. This article is an open access article distributed under the terms and conditions of the Creative Commons Attribution License (http://creativecommons.org/licenses/by/4.0/). 


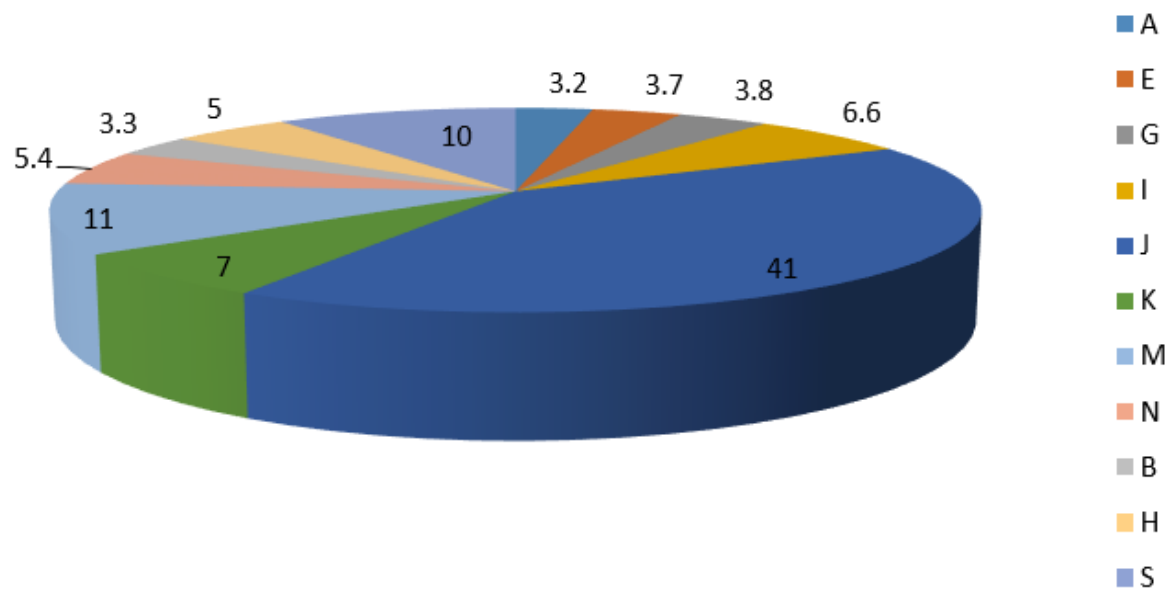

Figure 1: The structure of the general morbidity of rescuers

$A$ - some infectious and parasitic diseases; $B$ - viral infections; $E$ - diseases of the endocrine system; $G$ - diseases of the nervous system; $H$ - diseases of the eye and its adnexa; I - diseases of the circulatory system; I - respiratory diseases; $K$-diseases of the digestive system; $M$ - diseases of the musculoskeletal system; $N$-diseases of the genitourinary system; $S$ - traumas, poisoning and some other consequences of exposure to external causes

\section{MATERIALS AND METHODS}

To achieve the goal, the following research methods were used:

1. Sociological survey of rescuers, who took part in the aftermath of emergency situations of natural and man-made nature.

2. Information-analytical analysis of legislative and regulatory documents, reports and current documents, modern scientific-bibliographic sources.

3. Statistical.

The research material was tools of public health policy and regulation, statistical compendiums of the Ministry of Public Health, the Committee for Emergency Situations of the Ministry of Internal Affairs of the Republic of Kazakhstan. To study various aspects of the organization of medical and psychological rehabilitation, we conducted a comprehensive study of the health status of rescuers of the largest metropolis of Kazakhstan, Almaty, based on data from reports on registered diseases, their outcomes and causes of temporary disability for 2012-2017 and rehabilitation needs based on a specially designed questionnaire.

\section{RESULTS}

The criterion for inclusion in the study - mandatory participation in rescue and emergency work in the aftermath of emergencies. The criterion of exclusion - work as a rescuer for less than 1 year. The period of 1 year was regarded by us as sufficient for the formation of disorders due to participation in the aftermath of emergencies.

The study involved 551 rescuers, including firefighters - 271 (49.1\%), climbers (mine-rescue worker) - 69 (12.5\%), divers - 37 (6.7\%), health workers/psychologists - 54 (9.8\%), others - 120 (21.9\%).

Distribution by gender revealed the prevalence of men (87\%), which is associated with the specificity of the exposure of female rescuers to an increased risk of both physical and psychological trauma, which must be taken into account when conducting rescue operations (13).

The age of the examined $-19-60$ years, the average age $-(33.88+0.75)$ years. The work experience as a rescuer is 0 13 years, the average work experience $(4.43+0.28)$ years.

In the structure of the general morbidity of rescuers, the main classes of diseases were ranked as follows: $1^{\text {st }}$ place $(41 \%)$ - respiratory diseases; $2^{\text {nd }}$ place $(11 \%)$ - diseases of the musculoskeletal system and connective tissue; $3^{\text {rd }}$ place (10\%) - traumas, poisonings and some other consequences of exposure to external causes (Figure 1).

The absolute number of primary diseases for the study period - 1703, and labor losses - 41558 days. In the structure of days of labor losses, respiratory diseases occupied the $1^{\text {st }}$ place $(36 \%) ; 2^{\text {nd }}$ place - traumas, poisonings and some other consequences of external causes (23\%); $3^{\text {rd }}$ place - diseases of the musculoskeletal system and connective tissue (10\%). Places from the $4^{\text {th }}$ to the $6^{\text {th }}$ took pregnancy, childbirth and the postpartum period, circulatory system diseases and 
Table 1: Distribution of respondents by answers to the question: "Do mandatory medical examinations conduct to You?" (in absolute numbers and percentages)

\begin{tabular}{ccc}
$\begin{array}{c}\text { Do mandatory medical examinations conduct to You? (1 time per year, } \mathbf{1} \text { hour before the start of the } \\
\text { work shift, other) }\end{array}$ & Absolute numbers & Percentage \\
\hline Yes & 472 & 85,7 \\
\hline No & 37 & 6,7 \\
\hline Difficult to answer & 42 & 7,6 \\
\hline Total & 551 & 100 \\
\hline
\end{tabular}

Table 2: Distribution of respondents by answers to the question: "Did any health problems, psycho-emotional state after participating in rescue and emergency work observe at You?" (in absolute numbers and percentages)

\begin{tabular}{ccc}
\hline $\begin{array}{c}\text { "Did any health problems, psycho-emotional state after participating in rescue and emergency work } \\
\text { observe at You?" (in absolute numbers and percentages) }\end{array}$ & Absolute numbers & Percentage \\
\hline Yes & 498 & 90,3 \\
\hline No & 36 & 6,5 \\
\hline Difficult to answer & 17 & 3,1 \\
\hline Total & 551 & 100 \\
\hline
\end{tabular}

Table 3: Distribution of respondents by answers to the question: "If yes, then what kind of health problems were?" (in absolute numbers and percentages)

\begin{tabular}{ccc}
\hline If yes, then what kind of health problems were? & Absolute numbers & Percentage \\
\hline Wounds (contusions, traumas, injuries) & 114 & 22,9 \\
\hline Lesions from the effects of chemical, bacteriological, radiation factors & 7 & 1,4 \\
\hline Acute somatic and infectious diseases & 75 & 15,1 \\
\hline Exacerbation of chronic diseases & 86 & 17,3 \\
\hline Psycho-emotional and psychosomatic diseases & 201 & 15 \\
\hline Other & 3 & 15 \\
\hline Total & 498 & 100 \\
\hline
\end{tabular}

diseases of the digestive system. Their share in the overall morbidity structure ranged from 6 to $4.6 \%$. These 6 classes of diseases gave $86.0 \%$ of all days of labor losses.

The most common causes leading to disability were circulatory system diseases $-47.2 \%$; diseases of the musculoskeletal system and connective tissue - 11.1\%; tuberculosis, endocrine system diseases and neoplasms $-8.3 \%$ each. These 3 classes of diseases accounted for $88.9 \%$ of the total number of cases of rescuers' disability.

In the structure of mortality by disease classes, $50 \%$ of cases accounted for the death of rescuers from traumas; $21.4 \%$ for mortality from neoplasms; $20 \%$ of cases are deaths from coronary heart disease.

The study of the health status of rescuers allowed us to establish priority areas for the provision of medical care and rehabilitation:

- primary prevention of diseases of the respiratory system, circulatory system and traumatism prevention;

- comprehensive medical and psychological rehabilitation, aimed at restoring the ability to work and preventing the disability of rescuers.

Questioning of rescuers, who participated in emergency response showed, that $85.7 \%$ of respondents indicated, that they had to undergo mandatory medical examinations: once a year, 1 hour before the start of the work shift (during the emergency response before and after the work shift), while $6.7 \%$ of respondents do not undergo mandatory medical examinations, $7.6 \%$ find it difficult to answer (Table 1).

The overwhelming majority of respondents $90.4 \%$ note health problems, psycho-emotional state after participating in rescue and emergency work, and only $6.5 \%$ of respondents answered this question negatively (Table 2).

The majority of surveyed rescuers 201 (40.3\%) report psycho-emotional and psychosomatic diseases after participating in rescue and emergency work, which indicates the leading role of psychological factors in the development of somatic pathology and the possibility of health recovery through influencing the psycho-physiological state of a person (Table 3).

$82.6 \%$ of respondents noted, that they needed medical rehabilitation, and only $6.9 \%$ noted, that there was no need for rehabilitation (Table 4). 
Table 4: Distribution of respondents by answers to the question: "In your opinion, during the work as a rescuer, did You need medical rehabilitation?" (in absolute numbers and percentages)

In your opinion, during the work as a rescuer, did You need medical rehabilitation?

Absolute numbers Percentage

\begin{tabular}{ccc}
\hline & Absolute numbers & Percentage \\
\hline Yes & 456 & 82,6 \\
\hline No & 38 & 6,9 \\
\hline Difficult to answer & 57 & 10,3 \\
\hline Total & 551 & 100 \\
\hline
\end{tabular}

Table 5: Distribution of respondents by answers to the question: "What form of rehabilitation did You need?" (in absolute numbers and percentages)

\begin{tabular}{ccc}
\hline What form of rehabilitation did You need? & Absolute numbers & Percentage \\
\hline Outpatient care & 184 & $40,4 \%$ \\
\hline Inpatient care & 132 & $28,9 \%$ \\
\hline Rehabilitation treatment & 71 & $15,6 \%$ \\
\hline Spa treatment & 69 & $15,1 \%$ \\
\hline Total & 456 & 82,7 \\
\hline
\end{tabular}

Table 6: Distribution of respondents by answers to the question: "Assess on a scale the quality of the medical rehabilitation You received" (in absolute numbers and percentages)

\begin{tabular}{ccc}
\hline Assess on a scale the quality of the medical rehabilitation You received & Absolute numbers & Percentage \\
\hline Very good & 97 & 34,3 \\
\hline Good & 81 & 28,6 \\
\hline Moderately & 54 & 19,1 \\
\hline Bad & 7 & 2,5 \\
\hline Very bad & 5 & 1,8 \\
\hline Difficult to answer & 13,7 \\
\hline Total & 100 \\
\hline
\end{tabular}

Table 7: Distribution of respondents by answers to the question: "Do psychological assistance provide to You before/after participating in emergency response?" (in absolute numbers and percentages)

\begin{tabular}{ccc}
\hline Do psychological assistance provide to You before/after participating in emergency response? & Absolute numbers & Percentage \\
\hline Yes & 375 & 68,1 \\
\hline No & 127 & 23 \\
\hline Difficult to answer & 49 & 8,9 \\
\hline Total & 551 & 100 \\
\hline
\end{tabular}

$283(62.1 \%)$ of needy rescuers received medical rehabilitation, 173 (37.9\%) did not receive rehabilitation due to the lack of specialists in rehabilitation in the community; difficulties in obtaining a rehabilitation quota in the framework of the guaranteed volume of free medical care; the lack of a specialized rehabilitation center, as well as the respondent's refusal of rehabilitation and other reasons.

$40.4 \%$ of respondents needed rehabilitation in conditions of polyclinic, and $28.9 \%$ - in the hospital. The need for rehabilitation and sanatorium-and-spa treatment is noted by $15.6 \%$ and $15.1 \%$, respectively (Table 5).

The number of rescuers, receiving psychological assistance before / after participating in emergency response is 3 times higher than those, who do not visit a psychologist (Table 7).

Psychological assistance "very good" helps in the rehabilitation of the psycho-emotional state of $39.8 \%$ of respondents; "good" - 23.2\% of respondents; "moderately" - 17.3\% of respondents, "bad" and "very bad"- 7.2 and $1.3 \%$ of respondents, respectively (Table 8 ). 
Table 8: Distribution of respondents by answers to the question: "If yes, then how does psychological assistance help in the rehabilitation of Your psycho-emotional state?" (in absolute numbers and percentages)

If yes, then how does psychological assistance help in the rehabilitation of Your psycho-emotional state? Absolute numbers Percentage

\begin{tabular}{ccc}
\hline & 39,8 \\
\hline Very good & 149 & 87 \\
\hline Good & 65 & 17,2 \\
\hline Moderately & 27 & 7,2 \\
\hline Bad & 5 & 1,3 \\
\hline Very bad & 42 & 11,2 \\
\hline Difficult to answer & 100 \\
\hline
\end{tabular}

Table 9: Distribution of respondents by answers to the question: "In your opinion, during the work as a rescuer, did You need psychological rehabilitation?" (in absolute numbers and percentages)

In your opinion, during your work as a rescuer, did You need psychological rehabilitation?

\begin{tabular}{ccc}
\hline In your opinion, during your work as a rescuer, did You need psychological rehabilitation? & Absolute numbers & Percentage \\
\hline Yes & 303 & 55 \\
\hline No & 150 & 27,2 \\
\hline Difficult to answer & 98 & 17,8 \\
\hline Total & 551 & 100 \\
\hline
\end{tabular}

Table 10: Distribution of respondents by answers to the question: "If You received psychological rehabilitation, then where?" (in absolute numbers and percentages)

\begin{tabular}{ccc}
\hline If You received psychological rehabilitation, then where? & Absolute numbers & Percentage \\
\hline At the place of work by psychologists & 203 & 79 \\
\hline In the clinic by place of residence & - & - \\
\hline In the hospital & 9 & - \\
\hline In a rehabilitation center & - & - \\
\hline Other & 17,5 & 15 \\
\hline Total & 257 & 100 \\
\hline
\end{tabular}

Table 11: Distribution of respondents by answers to the question: "Rate on a scale the quality of the psychological rehabilitation You received" (in absolute numbers and percentages)

\begin{tabular}{ccc}
\hline Rate on a scale the quality of the psychological rehabilitation You received & Absolute numbers & Percentage \\
\hline Very good & 85 & 33,1 \\
\hline Good & 95,8 \\
\hline Moderately & 54 & 21 \\
\hline Bad & 2 & - \\
\hline Very bad & - & 24 \\
\hline Difficult to answer & 9,3 \\
\hline Total & 100 \\
\hline
\end{tabular}

More than half of respondents (55\%) noted the need for psychological rehabilitation, $27.2 \%$ of respondents answered negatively, $17.8 \%$ of respondents found it difficult to answer this question (Table 9 ).

Most respondents 203 (79\%) received psychological assistance from in-house psychologists of the emergency services, 9 (3.5\%) respondents were provided with inpatient treatment, and 45 (17.5\%) indicated other sources (friends, relatives, neighbors, etc.).

The quality of the received psychological rehabilitation was evaluated by $33.1 \%$ and $35.8 \%$ of respondents as "very good" and "good", respectively, which indicates a high level of training of psychologists for work in emergency situations (Table 11).

\section{DISCUSSION AND CONCLUSION}

Thus, the study of the health status of rescuers and the conducted survey indicate the importance of a system of early prevention and rehabilitation of rescuers. Content-analysis of legal documents, regulating the provision of medical assistance in emergency situations in Kazakhstan, showed, that there are no specialized rehabilitation teams in the country at the emergency medical care stage, as a result of which victims do not have timely access to rehabilitation (1420). The rehabilitation of rescuers is carried out in the Republic of Kazakhstan by state organizations of public health within the guaranteed volume of free medical care $(21,22)$. 
A rather high need for rehabilitation requires the creation of a specialized center for the rehabilitation of rescuers and people, affected in natural and man-made emergencies. Development of the infrastructure of rehabilitation organizations, standardization of services, systemic training of rehabilitation specialists, creation of specialized medical rehabilitation teams to ensure victims' early access to rehabilitation are essential for supporting international disability policy and consistent with the UN Convention on the Rights of Persons with Disabilities, which has been ratified by Kazakhstan in May 2015.

\section{REFERENCES}

1. Grebenyuk AN, Kushnir LA. Assessment of occupational risk to the health of firefighters from exposure to chemicals. Med. of labor and industrial ecology, 2010;12:10-4.

2. Banes CJ. Firefighters' cardiovascular risk behaviors. Workplace Health Saf., 2014;62(1):27-34. https://doi.org/10.1177/216507991406200105 PMid:24571052

3. Baxter CS, Hoffman JD, Knipp MJ, et al. Exposure of Firefighters to Particulates and Polycyclic Aromatic Hydrocarbons. J. Occup. Environ. Hyg., 2014:10.

4. Gaughan DM, Piacitelli CA, Chen BT, et al. Exposures and Cross-shift Lung Function Declines in Wildland Firefighters. J. Occup. Environ. Hyg., 2014. https://doi.org/10.1080/15459624.2014.895372 PMid:24568319

5. Bodurova DF. Study of the adaptive abilities of firefighters in emergency situations. Science and Business: ways of development, 2012;6(12):14-20.

6. Preobrazhensky VN, Beganova TV, Filippova GE. Possibility of early diagnosis of adaptive disorders in people with hazardous occupations. Development of sanatorium-resort care, rehabilitation and medical rehabilitation: All-Russian Forum, 2010:503-504.

7. Pronina GA, Pyatibrat ED, Batskov SS, et al. Assessment of changes in personal characteristics and quality of life associated with metabolic syndrome in rescuers EMERCOM of Russia. Psychotherapy Herald, 2013;48(53):52-6.

8. Biggs QM, Fullerton CS, Reeves JJ, et al. Acute stress disorder, depression, and tobacco use in disaster workers following 9/11. Am. J. Orthopsychiatry, 2010;80(4):586-92. https://doi.org/10.1111/j.1939-0025.2010.01063.x PMid:20950299

9. Molchanov LN, Redkin Al. Viability as a determinant of the state of mental burnout in rescuers EMERCOM. Prospects of science and education, 2014;1(7):216-23.

10. Fisun AYa, Shegolkov AM, Yudin VE. Priority tasks of the medical service of the Armed Forces of the Russian Federation for the implementation of the Federal Target Program for the Rehabilitation of Disabled People due to the war and military injuries and their execution. Actual problems of medical rehabilitation: Coll. scientific works, 2008:37-8.

11. Pek E, Martai I, Marton J, et al. Health surney of ambulance workers with a generic questionnaire (SF-36). Orv. Hetil., 2013;154(47):1865-72. https://doi.org/10.1556/OH.2013.29746 PMid:24240523

12. Poston WS, Haddock CK, Jahnkeet SA, et al. An examination of the benefits of health promotion programs for the national fire service. BMC Public Health, 2013;13:805. https://doi.org/10.1186/1471-2458-13-805 PMid:24007391 PMCid:PMC3846399

13. Sinden $\mathrm{K}, \mathrm{MacDermid} J$, Buckman $\mathrm{S}$, et al. A qualitative study on the experiences of female firefighters. Work, 2013;45(1):97-105. https://doi.org/10.3233/WOR-121549 PMid:23241712

14. Code of the Republic of Kazakhstan dated September 18, 2009 № 193-IV "On the health of the people and the health care system".

15. Law of the Republic of Kazakhstan dated April 11, 2014 № 188-V "On Civil Protection".

16. Government Decree of the Republic of Kazakhstan of June 17, 2010 № 608 "On Approval of the Rules for the Provision, Types and Volume of Medical Assistance in Emergency Situations". Available at: http://adilet.zan.kz/rus/docs/P100000608_

17. Order of the Minister of Public Health of the Republic of Kazakhstan dated December 27, 2013 № 759 "On approval of the standard for organizing the provision of medical rehabilitation to the population of the Republic of Kazakhstan".

18. Zavidić T, Lovrinić Đ. Elderly Patients Treated in Selected Family Medicine Offices in Central Istria and Their Habits. Journal of Clinical and Experimental Investigations, 2018;9(1):34-9. https://doi.org/10.5799/jcei.413069 
19. Shital P, Mirza M, Kadam M. Thoracic manifestations of Gynecological tumors: Airway and lung parenchymal involvement commoner in endometrial and ovarian cancers while pleural and interstitial involvement is predominant in cervix malignancies. European Journal of General Medicine, 2018;15(1). https://doi.org/10.29333/ejgm/81728

20. Heidary S, Riahi A. Study of $\alpha-1$ Antitrypsin Serum and its Effects on Chronic Inflammation in Diabete Patients. Medbiotech Journal, 2018;02(01):01-7.

21. Al Tariq Z. Clinical, Biochemical and Immunological Profiles of HIV Patients Developing Immune Reconstitution Inflammatory Syndrome (IRIS). Medbiotech Journal, 2018;02(01):21-8.

22. Mehrabifar A, Mansouri A, Gholami K, Ghaeli P, Javadi M. Investigation of Medication Errors in a Teaching Psychiatric Hospital using Chart Reviews. Medbiotech Journal, 2017;01(02):60-4.

$\diamond \diamond \diamond \diamond \diamond \diamond \diamond$

http://www.ejgm.co.uk 